\title{
Teleseismic Travel-Time Delays in the Las Vegas Basin
}

\author{
by Hrvoje Tkalčić, Arthur J. Rodgers, Nicholas Rawlinson, \\ Darlene J. McEwan, ${ }^{*}$ and Catherine M. Snelson ${ }^{\dagger}$
}

\begin{abstract}
A temporary broadband seismic array was deployed in the Las Vegas basin (LVB), home to one of the fastest growing communities in the United States, to investigate structure in this deep $(\sim 5 \mathrm{~km})$ sedimentary basin. To constrain basin velocity structure, we measured the differential travel time of teleseismic $P$ waves by waveform cross correlation relative to a station near the basin's edge. The range of the travel-time delays is significant (up to $0.5 \mathrm{sec}$ ), and the pattern of travel-time delays is independent of the back azimuth of the incoming energy, suggesting that the near-surface structure controls the delay times. Assuming the reported basin geometry of Langenheim et al. (2001), we modeled the average delay times at the basin stations to estimate the average $P$-wave velocity structure within the basin. The average times can be modeled with relatively fast $P$-wave velocities $(4.5 \mathrm{~km} / \mathrm{sec})$ in the deepest part of the basin (below $2 \mathrm{~km}$ ), which is in agreement with the $P$-wave velocities of the deep part of the basin from recent seismic refraction profiling (Snelson et al., 2004) and low velocities $(1.5 \mathrm{~km} / \mathrm{sec})$ in the shallow basin $(200 \mathrm{~m})$. We also performed computations based on the fast marching method approach to solve the forward problem and inversion for basin geometry. This method is used to map the traveltime residual information extracted from the array to variations in subsurface seismic structure. While the coverage of teleseismic data is insufficient to independently resolve the steeply dipping footwall of the basin in its eastern part, we found that the footwall block is likely to be shifted farther west than indicated by the gravimetrybased model. The basin edge is probably related to the Frenchman Mountain fault and its inferred location closer to Las Vegas will result in stronger ground motion during an earthquake.

We report site response from teleseismic earthquakes and compare it with previously published site response from regional earthquakes using the standard spectral ratio method. The useful bandwidth of large teleseismic and regional events for standard spectral ratio measurements is $0.1-1.0$ and $0.2-5.0 \mathrm{~Hz}$, respectively. Remarkably, we find excellent agreement between the two measurement types within the overlapping frequency band $(0.2-1.0 \mathrm{~Hz})$. This indicates that the amplification arises from the structure in the immediate vicinity of the recording station, regardless of the nature of the incoming energy - vertically propagating teleseismic $S$ body waves or horizontally propagating regional surface waves. The results of these investigations indicate that low velocities are present near the surface in LVB, likely related to relatively recent (Quaternary) alluvial and lakebed sediments at the surface. Fast velocities in the deeper basin probably result from older formations.
\end{abstract}

Introduction

Las Vegas Valley (LVV), Nevada, is located in the central Basin and Range province and is filled with consolidated

"Present address: ExxonMobil Exploration Company, Houston, Texas 77210-4778.

'Present address: New Mexico Institute of Mining and Technology, Socorro, New Mexico 87801.
Tertiary and older sediments as well as semi- to unconsolidated Quaternary alluvial and lacustrine sediments, which are fault bounded (e.g., Tabor, 1982; Wernicke et al., 1988; Plume, 1989). Recent work has shown that at least eight Quaternary normal faults within the basin (Cashman fault, Eglington-Decatur fault, Frenchman Mountain fault, River Mountains fault, West Charleston fault, Whitney Mesa fault, 
Valley View fault, etc.) are tectonic in origin and not compaction driven as previously believed (Slemmons et al., 2001). These primarily north-south striking normal faults are capable of producing $M$ 6.5-7.0 earthquakes within the Valley (Slemmons et al., 2001). A recent study by Langenheim et al. (2001), based mostly on gravity measurements, estimated the basin depth and determined that the deepest portion of the basin was up to $5 \mathrm{~km}$ in the northeastern part of the valley, thinning to the southwest to less than $1 \mathrm{~km}$ (Fig. 1a). The existence of active faults and a deep sedimentary basin represents a set of circumstances that have been shown to result in considerably increased damage (see, e.g., Stidham, 1999 for a study on the Santa Clara Valley).

As part of a multidisciplinary effort, geologic, geotechnical, and seismic refraction studies were conducted recently to determine the lithologic and geophysical properties of the basin in order to better understand seismic-wave amplification and strong ground motion (e.g., Liu and Luke, 2004; Louie et al., 2004; Snelson et al., 2004; Rodgers et al., 2006). The engineering firm Blume and Associates operated a strong-motion seismograph network in the Las Vegas Valley during the time period of nuclear testing at the Nevada test site (NTS). Several studies of these data and earthquakes recorded during the operation of the network indicate increased ground-motion amplification within the basin (Davis and Lynch, 1970; Su et al., 1998; Rodgers et al., 2006). The Blume network was primarily located in the areas of the basin where population was concentrated (Fig. 1a). In order to provide constraints in the previously unsampled part of the Las Vegas basin (LVB), we deployed a broadband network in the northeastern deepest portion of the basin, where we might expect the highest ground amplifications due to thick sediments (Fig. 1a). Broadband instruments operated at SGS, F02, F04, F20, CHY, SQP, VAH, and ULV sites, while we employed short-period instruments at GPS, F23, and LVW. All instruments were continuous recording at 40 samples per second.

In a recent study (Rodgers et al. 2006), we reported site responses from historical recordings of NTS explosion and more recent regional earthquake recordings. In the same study, we modeled site amplifications using two-dimensional (2D) elastic finite difference simulations and found that site response could be successfully modeled with a low-velocity layer near the surface (with shear velocities 600-750 m/ sec and a thickness of 100-200 m).

In an attempt to provide additional constraints on the basin structure, we analyzed the waveforms obtained from the broadband stations and measured high precision differential travel time of teleseismic $P$-wave arrivals relative to a reference station. We then applied a forward and inversion modeling approach to explain the pattern and amplitude of the observed travel-time delays in terms of the reported basin geometry and depth-dependent velocity structure. Additionally, we report site response measured from large teleseismic earthquakes and compare it with the site response measured from smaller regional earthquakes.
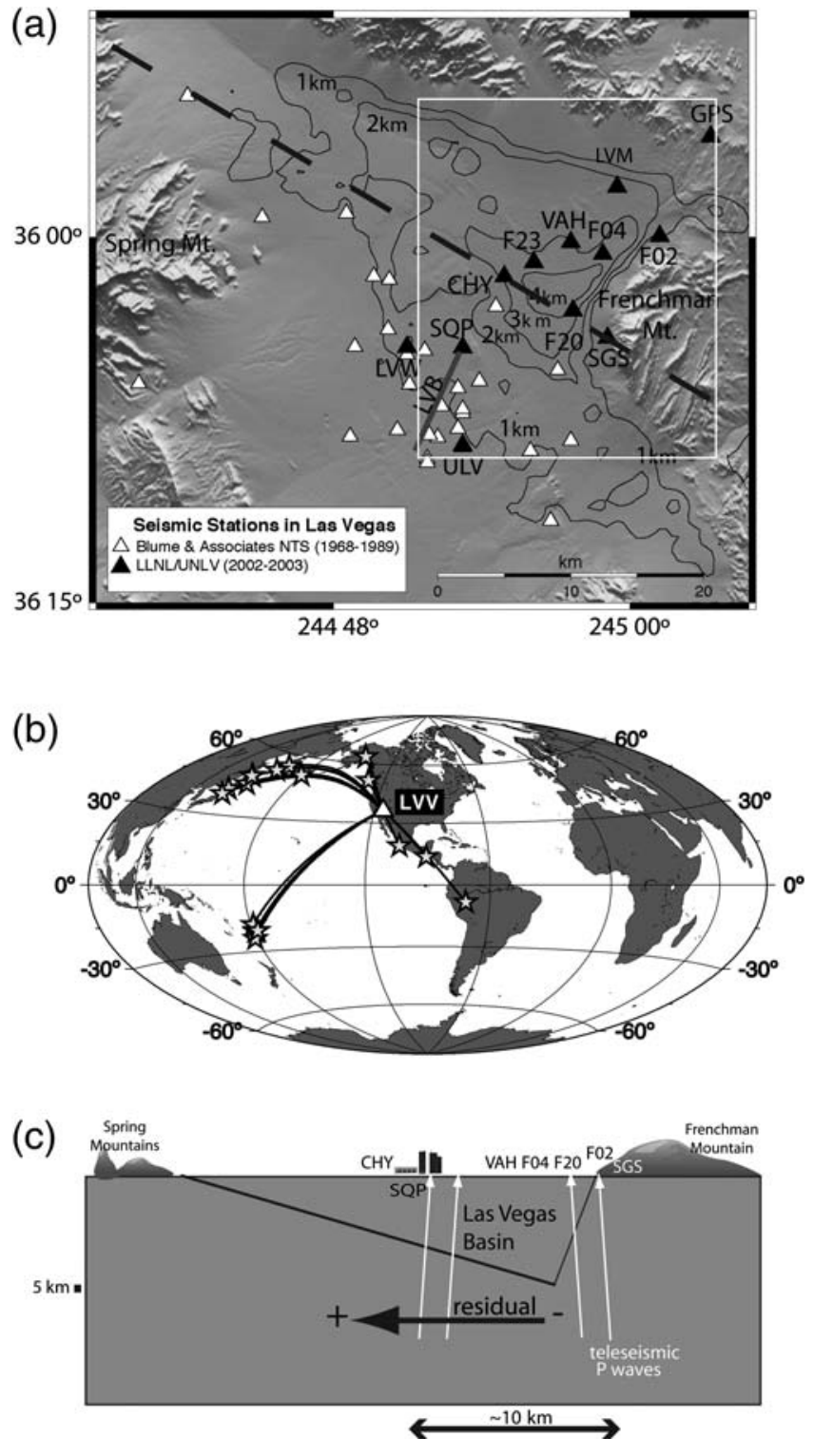

Figure 1. (a) Map of the Las Vegas Valley with depth contours (expressed in kilometers) from Langenheim et al. (2001) model. The gray solid line is the location of Las Vegas Boulevard. White triangles are the Blume network operated in the past, while black triangles are the temporary broadband network operated between September 2002 and January 2003, whose data are used in this study. The dashed line is a profile for the vertical cross section shown in (c). The outlined rectangular area is used in travel-time analysis shown in Figure 3. (b) Geographical distribution of the teleseismic events used in this study. The position of the Las Vegas Valley (triangle) is shown with respect to the events used in traveltime and site response analysis (stars). Surface projections of greatcircle paths are shown by solid lines. (c) A schematic vertical cross section through the LVB and near-vertical teleseismic waves. Stations for Figure 1a are shown at the surface. The position of the city of Las Vegas is indicated by buildings. The change in the sign of the observed differential travel-time residuals is illustrated by a black arrow. 


\section{Differential Travel-Time Measurements}

During the operation of our broadband seismic network in LVV (September 2002-January 2003), more than 30 teleseismic events with moment magnitudes larger than 6.0 were recorded. The locations of the analyzed events in this study are shown in Figure 1b. A schematic vertical cross section through the LVB (dashed line in Fig. 1a) and near-vertical teleseismic waves are shown in Figure 1c. Ideally, we would consider station SGS - situated at a rock site - to be a reference station for our differential travel-time measurements, as it has a low noise and records waveforms that do not vary significantly from one earthquake to another from the same source region (Tkalčić et al., 2003; McEwan, 2005). However, due to problems in operation of the SGS station, data from several earthquakes were either of low quality or missing. Another station, F02, which is located in the northeastern edge of the basin, recorded data of excellent quality and we used its waveforms as a reference for differential traveltime measurements.

We measured and analyzed teleseismic $P$-wave traveltime recorded by the LVV network. We chose 12 events for which we could determine clear $P$-wave arrivals. The origin times, locations, and magnitudes from the National Earthquake Information Center (NEIC) catalog for these events are listed in Table 1, and their path geometry is shown in Figure $1 \mathrm{~b}$. The azimuthal coverage that we obtained using this configuration of events is relatively good, with the exception of a gap in the coverage from eastern azimuths. Because the sources in our case are far away from the network, the ray paths through the Earth for any given event to each individual station of our network are virtually the same. They differ only immediately beneath the receivers, so we expect that any difference in the travel-time data with respect to the one-dimensional (1D) model prediction must stem from the topography and shallow structure of the crust affecting the incident wave field in the LVB.

The broadband waveforms recorded at the LVV network from two teleseismic events are shown in Figure 2a,b. Most of the time, the noise level is low so that we can use unfiltered waveforms. When necessary, we band-pass filtered the waveforms with a Butterworth band-pass acausal filter of order 2 between 0.1 and $1.0 \mathrm{~Hz}$, in order to filter out the noise (Fig. 2c,d). This filter was decided on based on spectral analysis of recorded teleseismic waveforms, the signal-tonoise ratio being the highest in this particular frequency range. Acausal filtering does not impact measurements of differential travel time by cross correlation. We perform cross correlation of the reference $P$ waveform (i.e., only the first quarter of the $P$-arrival cycle) with $P$ waveforms of each station (shown for stations F04 and VAH in Fig. 2e,f), and we calculate the differential travel time between them. The estimated error in these measurements is about $0.05 \mathrm{sec}$ or less. In order to account for the differences in travel time among stations due to slightly different lengths of the path for each station for a given earthquake, we corrected each path according to the travel time estimated from the reference Earth model ak135 (Kennett et al., 1995). Finally, we computed residuals by subtracting the ak135 prediction from the observed differential travel time, according to

$$
\text { residual }=\left(t_{i}-t_{\text {ref }}\right)_{\mathrm{obs}}-\left(t_{i}-t_{\text {ref }}\right)_{\text {theor }},
$$

where $t_{i}$ is the $P$-wave travel time recorded at station $i$ and $t_{\text {ref }}$ is the $P$-wave travel time at the reference station. Subscripts obs and theor stand for observed and theoretical (predicted by the ak135 model) differential travel time.

\section{Analysis of Differential Travel Time and Forward Modeling of Basin}

In Figure 3, we plot the travel-time residuals with respect to station F02 for 12 teleseismic events (Table 1 and Fig. 1b). The observed absolute variation of residuals for a single event is typically greater than $0.2 \mathrm{sec}$, reaching as much as $0.5 \mathrm{sec}$ for the largest of the Sea of Okhotsk events, one of the best-recorded earthquakes. In these images, the average was removed to account for path-specific travel-time

Table 1

Events Used in Travel-Time Analysis in This Study

\begin{tabular}{cclrrrr}
\hline $\begin{array}{c}\text { Event Date } \\
(\mathrm{mm} / \mathrm{dd} / \mathrm{yyyy})\end{array}$ & $\begin{array}{c}\text { Event Time } \\
(\mathrm{hr} \text { min sec) }\end{array}$ & \multicolumn{1}{c}{ Region } & \multicolumn{1}{c}{$\begin{array}{c}\text { Latitude } \\
\left({ }^{\circ}\right)\end{array}$} & \multicolumn{1}{c}{$\begin{array}{c}\text { Longitude } \\
\left({ }^{\circ}\right)\end{array}$} & \multicolumn{1}{c}{$\begin{array}{c}\text { Depth } \\
(\mathrm{km})\end{array}$} & $\begin{array}{c}\text { Magnitude } \\
\left(M_{\mathrm{w}}\right)\end{array}$ \\
\hline $10 / 03 / 2002$ & $19: 05: 48.77$ & Tonga-Fiji & -20.991 & -179.016 & 621.1 & 6.3 \\
$10 / 12 / 2002$ & $20: 09: 11.46$ & Peru & -8.295 & -71.738 & 534.3 & 6.9 \\
$10 / 14 / 2002$ & $14: 12: 43.75$ & Japan & 41.174 & 412.249 & 61.4 & 6.1 \\
$10 / 16 / 2002$ & $10: 12: 21.13$ & Kamchatka & 51.952 & 157.323 & 102.4 & 6.2 \\
$11 / 03 / 2002$ & $22: 12: 41.52$ & Alaska & 63.514 & -147.453 & 4.2 & 7.2 \\
$11 / 07 / 2002$ & $15: 14: 06.76$ & Aleutians & 51.197 & 179.334 & 33.0 & 6.6 \\
$11 / 17 / 2002$ & $04: 53: 48.46$ & Sea of Okhotsk & 47.946 & 146.419 & 470.2 & 5.8 \\
$11 / 17 / 2002$ & $04: 53: 53.54$ & Sea of Okhotsk & 47.824 & 146.209 & 459.1 & 7.3 \\
$12 / 10 / 2002$ & $04: 27: 54.60$ & Tonga-Fiji & -24.139 & 179.240 & 530.6 & 6.1 \\
$01 / 04 / 2003$ & $05: 15: 03.84$ & Tong-Fiji & -20.570 & -177.661 & 378.0 & 6.5 \\
$01 / 21 / 2003$ & $02: 46: 47.74$ & Guatemala & 13.626 & -90.744 & 24.0 & 6.5 \\
$01 / 22 / 2003$ & $02: 06: 34.61$ & Mexico & 18.770 & -104.104 & 24.0 & 7.6 \\
\hline
\end{tabular}

Event origin time, location, and magnitude are from the NEIC catalog. 
(a) ORIGIN TIME: 21-JAN-2003 02:46:47.740 UNFILTERED DATA
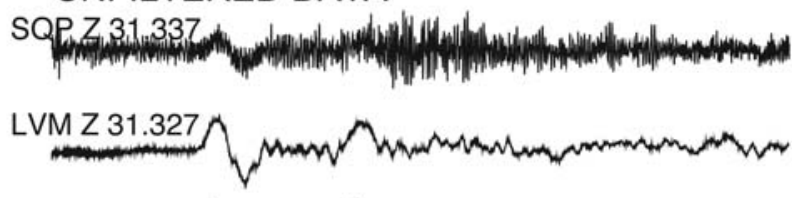

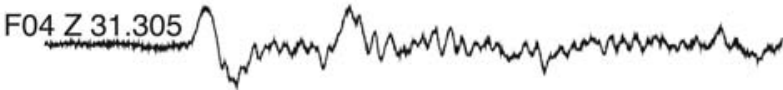

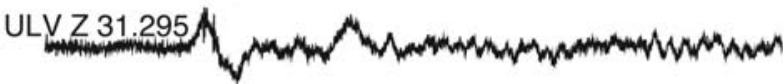

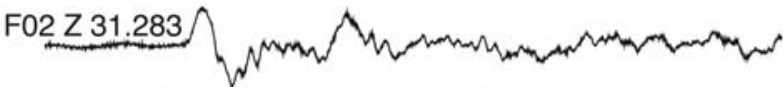
REGION: MEXICO; $M w=6.5 ; \mathrm{H}=24 \mathrm{~km}$

$\begin{array}{lllllll}0.0 & 10.0 & 20.0 & 30.0 & 40.0 & 50.0 & 60.0\end{array}$

(c) FILTERED DATA $(0.1-1.0 \mathrm{~Hz})$

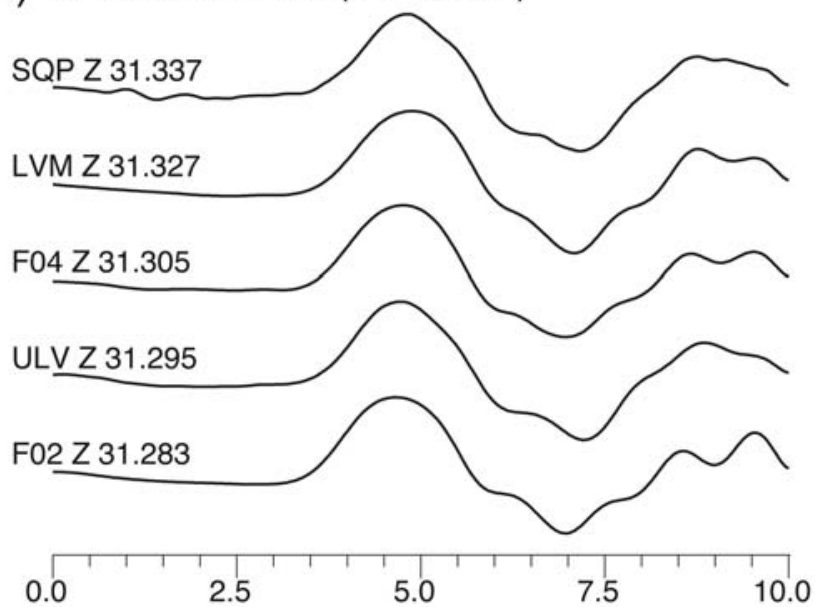

(e)

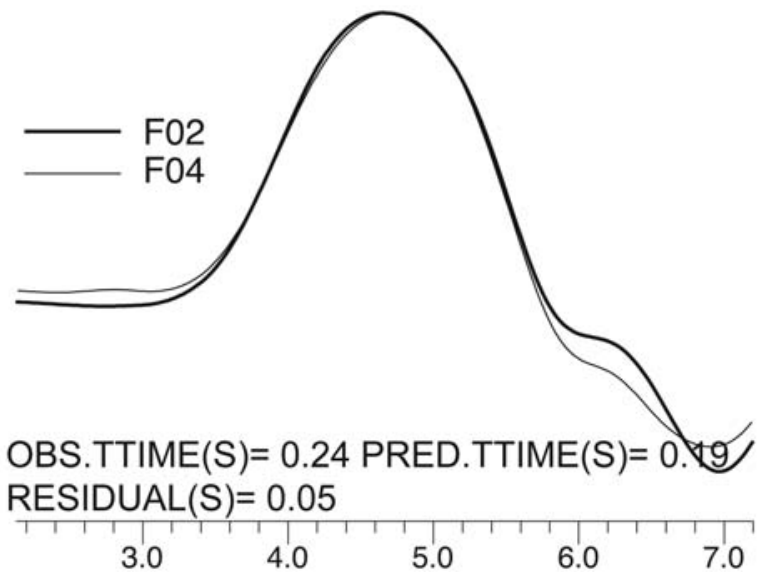

(b) ORIGIN TIME: 17-NOV-2002 04:53:53.540 UNFILTERED DATA SGS Z 69.261

F02 Z 69.237

F20 Z 69.231

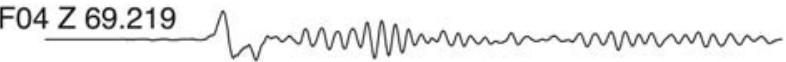

VAHZ 69.197 \N

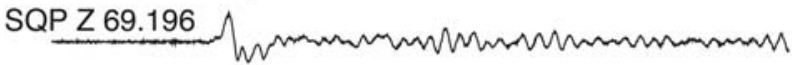

CHY Z 69.182

REGION: SEA OF OKHOTSK; $M w=7.3 ; \mathrm{H}=470 \mathrm{~km}$

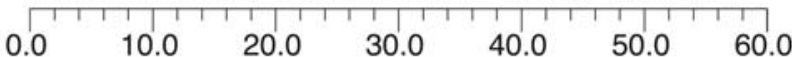

(d) FILTERED DATA $(0.1-1.0 \mathrm{~Hz})$

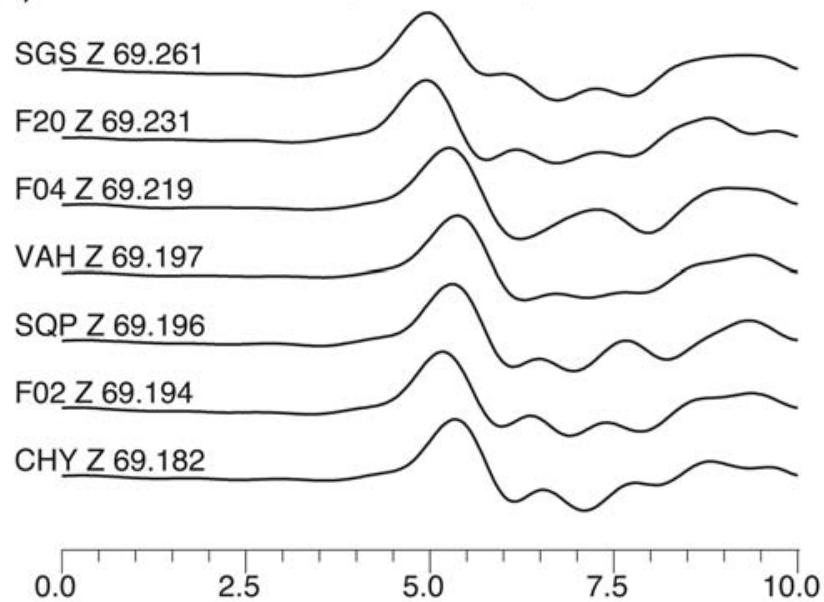

(f)

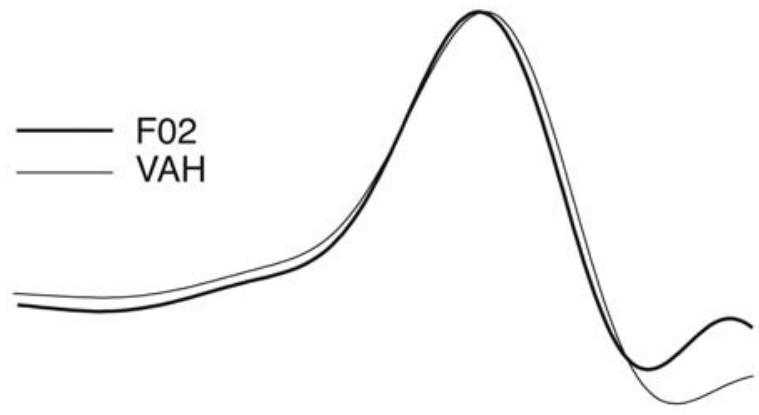

OBS. $\operatorname{TTIME}(\mathrm{S})=-0.08$ PRED $\cdot \operatorname{TTIME}(\mathrm{S})=-0.24$

RESIDUAL(S) $=0.16$

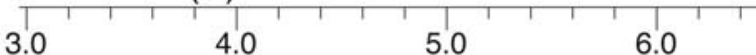

Figure 2. Two examples of unfiltered teleseismic data recorded on vertical components of LVV broadband instruments for (a) an event from Mexico and (b) an event from the Sea of Okhotsk. The numbers on the left-hand side indicate the epicentral distance in degrees. The same data as in (a) and (b), but band-pass filtered between 0.1 and $1.0 \mathrm{~Hz}$, are shown in (c) and (d). Examples of a differential travel-time measurement are shown in (e) and (f). The thick line represents the vertical component of referent waveform (F02), while the thin line is the vertical component waveform belonging to F04 (in [e]) and VAH (in [f]), respectively. The waveforms are time shifted so that the first quarters of the wavelengths overlap. The estimated measurement error is about $0.05 \mathrm{sec}$. The reference 2D Earth model is ak135 (Kennet et al., 1995). 


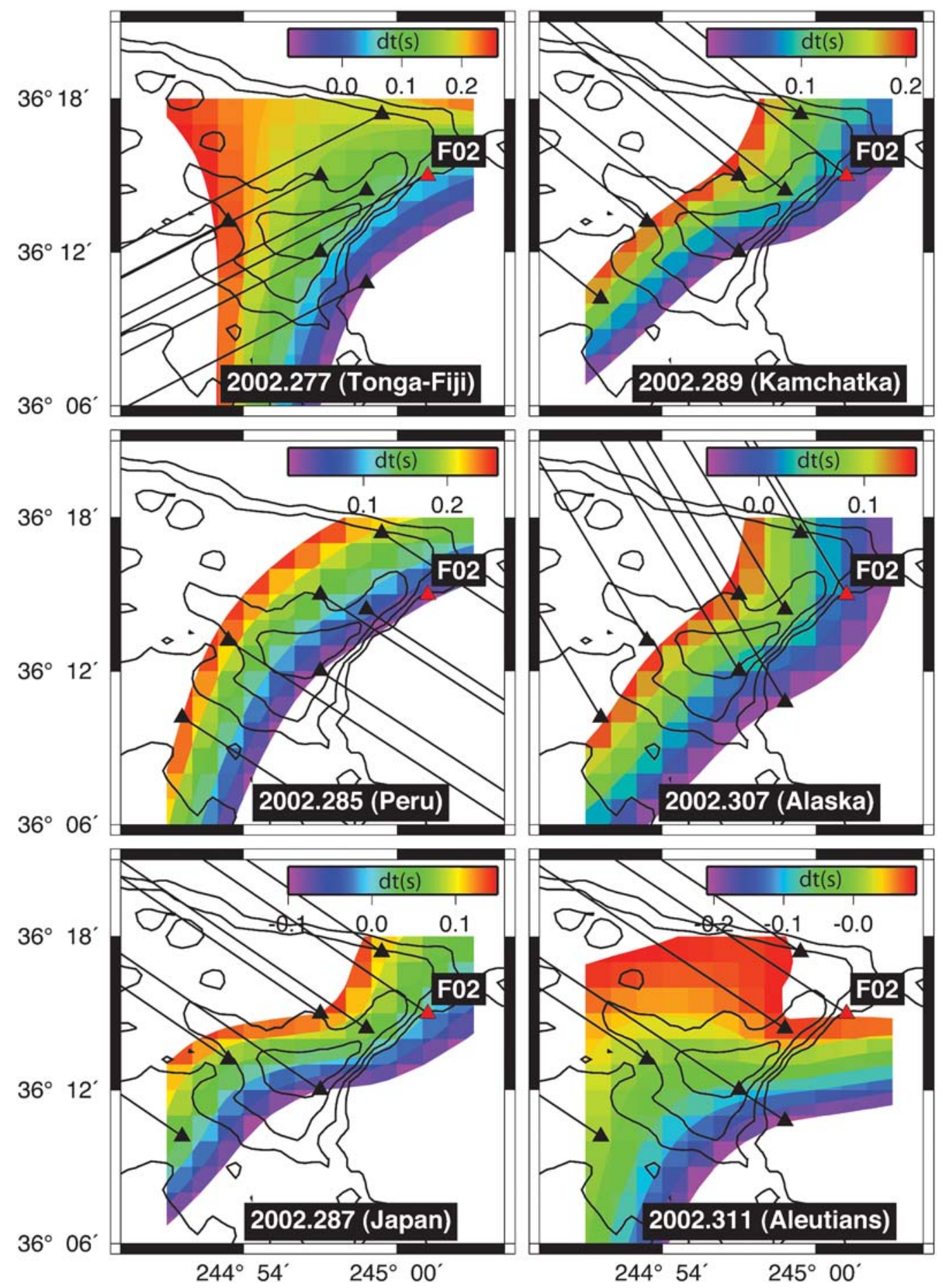

Figure 3. Differential $P$ travel-time residuals for 12 teleseismic events recorded in the Las Vegas Valley. Color contours show the value of the differential travel-time residuals (observed minus predicted travel-time difference between the $P$ waveforms of F02 [red triangle] and any given station [black triangles]). Each station has a black straight line at azimuth of ray path from the event. Black contour lines are the basin depth estimate from the Langenheim et al. (2001) model. The maximum variation in the residuals is about 0.5 sec. The depth contour interval is the same as in Figure 1a.

(Continued)

anomalies from ak135 for each event (which is why F02 does not always show a zero residual). We applied a continuous curvature algorithm to produce color surface contour plots of travel-time residuals (Wessel and Smith, 1991). The number and location of stations available for each event varies and somewhat determines the final shape of the contours, but the overall pattern of residuals and the gradient direction remain unchanged regardless of the direction of the incoming energy. Our resulting travel-time residual gradient coincides very well with the direction of the steepest basin slope (Lan- 

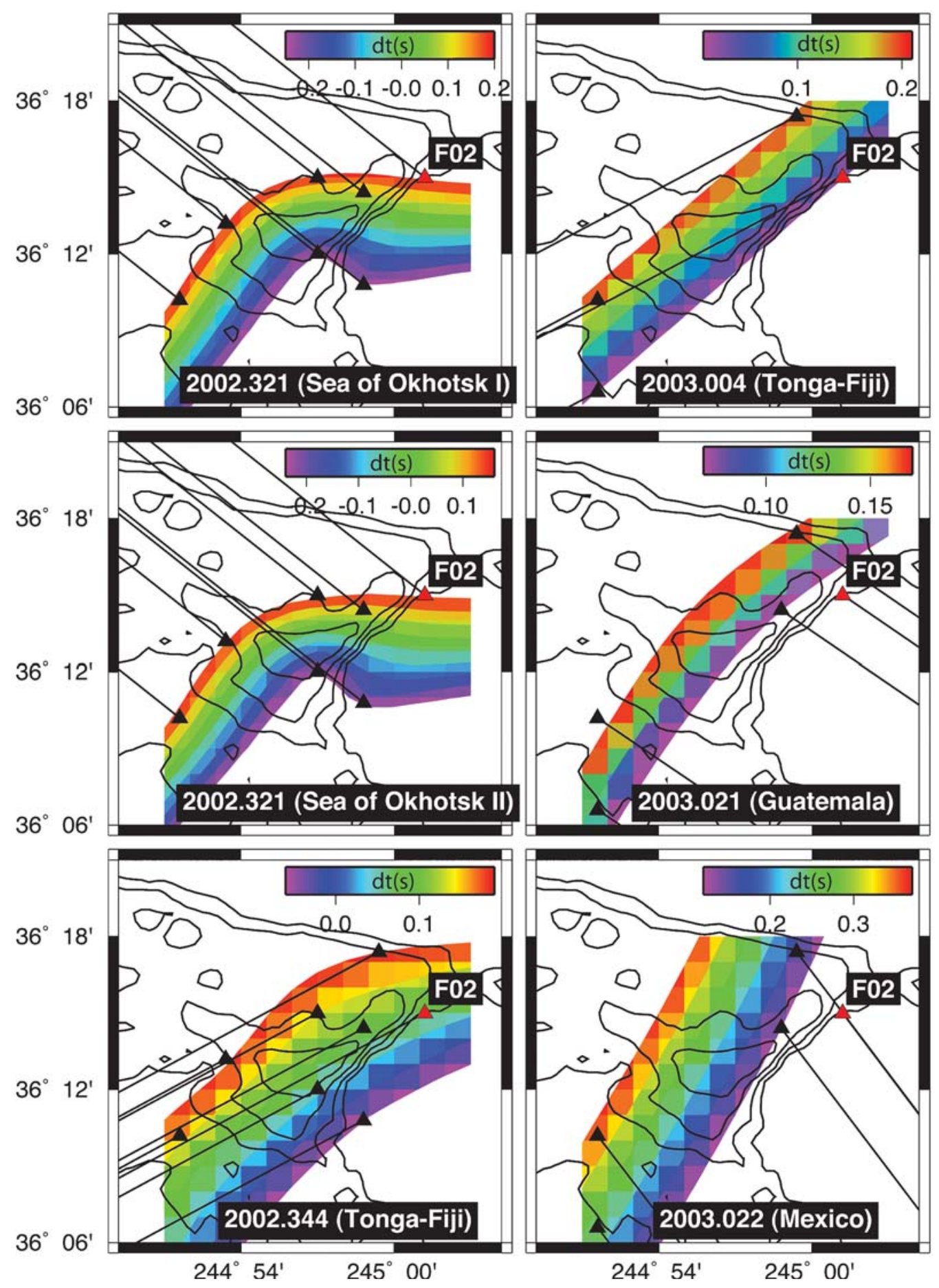

Figure 3. Continued.

genheim et al., 2001) shown by the basin depth isolines in Figure 3. At first glance, this could be an artifact caused by an elongated shape of the area defined by the configuration of the station locations in the basin for each particular event and the direction of incoming energy for most events, which is nearly perpendicular to this shape. However, the gradient does not change direction (nor does the sign) for the energy entering from the southwestern quadrant (Tonga-Fiji events) (Fig. 1b). We conclude that the observed signal comes from the structure on the receiver side of the paths. The amplitude spectra show a peak at $0.2 \mathrm{~Hz}$, and if we assume average propagation velocity to be about $5 \mathrm{~km} / \mathrm{sec}$, this results in wavelengths of about $25 \mathrm{~km}$. Therefore, it is not surprising that we observe coherency at the scale of about $10 \mathrm{~km}$. 


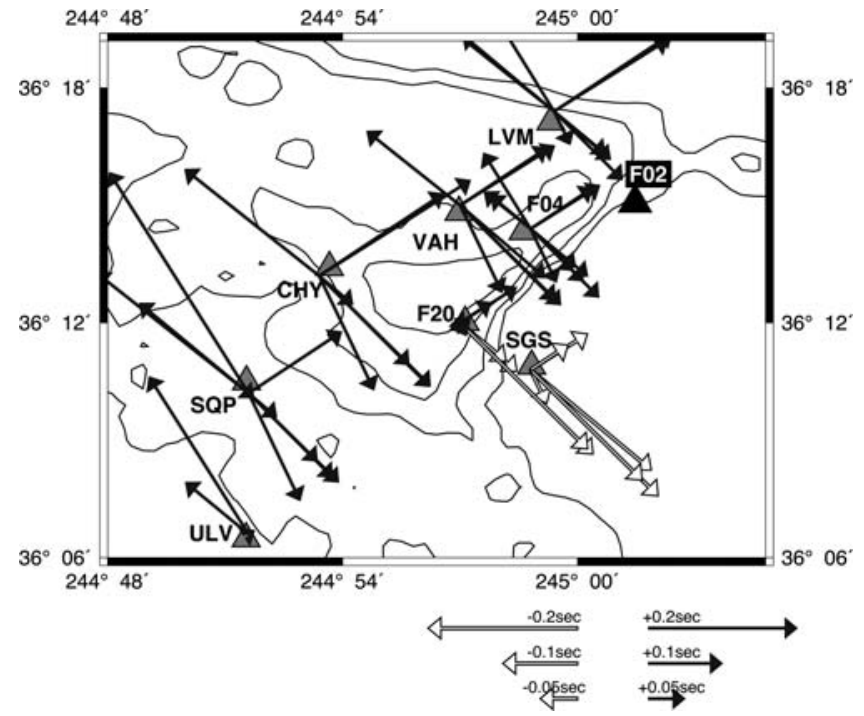

Figure 4. Differential travel-time residuals, plotted as vectors at each station. The size of the arrows shows the absolute value, while the color indicates the sign of residuals (see the legend). The arrows are oriented along the azimuth of the incoming waves. Contour lines are the basin depth estimate from the Langenheim et al. (2001) model.

In order to visualize travel-time residual measurements at each station, we constructed a rose of vectors showing the direction, the size, and the absolute sign of travel-time residuals with respect to the station F02 (Fig. 4). Table 2 shows the observed (column 7) and predicted (column 8) differen- tial travel time with respect to station F02, for the 4 October 2002 event taken as an example. The residual is shown in column 9 and indicated with the size of the vector. Negative residuals with respect to this station imply earlier $P$-wave arrivals than predicted by the radial ak135 model of the Earth, and they correspond to fast structure. Positive residuals indicate later $P$-wave arrivals corresponding to slow structure. There is general agreement between the sign of residuals and the reported basin vertical extent, whose low-velocity sediments slow down seismic waves.

In Table 3, we extracted measurements for all of the events for which we had station F04 travel time measured with respect to station F02. Thus, the event taken as an example in Table 2 represents the first row in Table 3. From Figure 4 and Table 3, one can see that in fact the residuals for F04 with respect to F02 are not only of the same sign, but they are very similar, ranging from 0.08 to $0.13 \mathrm{sec}$ (column 10). Because these two stations are close to each other, this is what is expected if the travel-time delays are strictly due the local structure. In fact, from Figure 4, it is clear that the residuals are of the same sign at all stations with the exception of SGS and F20 (SGS has only negative residuals). It is straightforward to explain large negative residuals at SGS due to fast wave velocities under Frenchman Mountain. However, F20, the site situated in the deepest part of the basin close to its eastern footwall portion (according to the Langenheim et al. [2001] model), also shows negative residuals, and will be discussed in the following paragraphs.

Table 2

Observed and Predicted Differential Travel Times and Residuals for Six Stations Recording the 4 October 2002 Event

\begin{tabular}{cccccccr}
\hline Station Name & $\begin{array}{c}\text { Station Latitude } \\
\left({ }^{\circ}\right)\end{array}$ & $\begin{array}{c}\text { Station Longitude } \\
\left({ }^{\circ}\right)\end{array}$ & $\begin{array}{c}\text { Distance } \\
\left({ }^{\circ}\right)\end{array}$ & Back Azimuth & Observed Difference & Predicted Difference & $\begin{array}{r}\text { Residual } \\
\text { (Fig. 5) }\end{array}$ \\
\hline CHY & 36.22 & -115.11 & 82.95 & 237.74 & -0.26 & -0.50 & 0.24 \\
F04 & 36.24 & -115.02 & 83.01 & 237.79 & -0.08 & -0.19 & 0.11 \\
F20 & 36.20 & -115.05 & 82.97 & 237.78 & -0.28 & -0.37 & 0.09 \\
LVM & 36.29 & -115.01 & 83.05 & 237.79 & 0.15 & -0.03 & 0.18 \\
SGS & 36.18 & -115.02 & 82.98 & 237.80 & -0.41 & -0.32 & -0.09 \\
VAH & 36.25 & -115.05 & 83.00 & 237.77 & -0.10 & -0.25 & 0.15 \\
\hline
\end{tabular}

Table 3

Observed and Predicted Differential Travel Time and Residuals at Station F04 with Station F02 as Reference

\begin{tabular}{|c|c|c|c|c|c|c|c|c|c|}
\hline $\begin{array}{l}\text { Event Date } \\
\text { (mm/dd/yyyy) }\end{array}$ & $\begin{array}{l}\text { Event Time } \\
\text { (hr min sec) }\end{array}$ & $\begin{array}{c}\text { Event Latitude } \\
\left({ }^{\circ}\right)\end{array}$ & $\begin{array}{c}\text { Event Longitude } \\
\left({ }^{\circ}\right)\end{array}$ & $\begin{array}{l}\text { Event Depth } \\
\quad(\mathrm{km})\end{array}$ & $\begin{array}{c}\text { Distance } \\
\left({ }^{\circ}\right)\end{array}$ & $\begin{array}{c}\text { Back } \\
\text { Azimuth }\end{array}$ & $\begin{array}{c}\text { Observed } \\
\text { Difference }\end{array}$ & $\begin{array}{l}\text { Predicted } \\
\text { Difference }\end{array}$ & $\begin{array}{l}\text { Residual } \\
\text { (Fig. 5) }\end{array}$ \\
\hline $10 / 04 / 2002$ & $19: 05: 48.770$ & -20.991 & -179.016 & 621.1 & 83.01 & 237.79 & -0.08 & -0.19 & 0.11 \\
\hline $10 / 12 / 2002$ & 20:09:11.460 & -8.295 & -71.738 & 534.3 & 60.13 & 128.51 & 0.23 & 0.15 & 0.08 \\
\hline $10 / 14 / 2002$ & $14: 12: 43.750$ & 41.174 & 142.249 & 61.4 & 75.43 & 310.47 & -0.04 & -0.12 & 0.08 \\
\hline $10 / 16 / 2002$ & $10: 12: 21.430$ & 51.952 & 157.323 & 102.4 & 61.13 & 315.08 & 0.01 & -0.12 & 0.13 \\
\hline $11 / 03 / 2002$ & $22: 12: 41.520$ & 63.514 & -147.453 & 4.2 & 33.69 & 334.31 & 0.03 & -0.05 & 0.08 \\
\hline $11 / 07 / 2002$ & $15: 14: 06.760$ & 51.197 & 179.334 & 33.0 & 48.15 & 309.68 & -0.06 & -0.16 & 0.10 \\
\hline $11 / 17 / 2002$ & $04: 53: 48.460$ & 47.946 & 146.419 & 470.2 & 69.22 & 314.68 & -0.01 & -0.11 & 0.10 \\
\hline $11 / 172002$ & $04: 53: 53.540$ & 47.946 & 146.419 & 470.2 & 69.22 & 314.68 & -0.03 & -0.11 & 0.08 \\
\hline $12 / 10 / 2002$ & $04: 27: 54.600$ & -24.139 & 179.240 & 530.6 & 86.32 & 236.58 & -0.08 & -0.18 & 0.10 \\
\hline $01 / 21 / 2003$ & $02: 46: 47.740$ & 13.626 & -90.774 & 24.0 & 31.30 & 129.79 & 0.26 & 0.19 & 0.07 \\
\hline $01 / 22 / 2003$ & $02: 06: 34.610$ & 18.770 & -104.104 & 24.0 & 19.89 & 148.17 & 0.23 & 0.11 & 0.12 \\
\hline
\end{tabular}


In Figure 5, we plotted differential travel-time delays for individual stations with respect to the station SGS and their averages (open diamonds) as a function of basin depth from the Langenheim et al. (2001) model. SGS waveforms were available for waveform comparison for only five events from Table 1. It is possible to establish a single linear trend (although arguably) between basin depth and travel-time delays for the stations located in the areas of the basin corresponding to shallower depths. However, it is not possible to continue such simple linear trend for stations F04 and F20. Nonetheless, from the rest of the data, assuming the basin depth model by Langenheim et al. (2001), we can estimate the best-fitting straight line (Fig. 5, dashed line).

Assuming a homogeneous structure everywhere in the basin, we calculated travel-time residuals relative to the station SGS as a function of basin depth. We assumed vertical incidence of teleseismic ray paths and compressional velocity of surrounding rocks equal to $5.93 \mathrm{~km} / \mathrm{sec}$, after Patton and Taylor (1984) and our study (Rodgers et al., 2006) in which we modeled site response in the basin using elastic finite difference technique. Given a constant velocity in the basin, this is a linear function. We then compared the slopes of the best-fitting straight line (Fig. 6, solid line) with

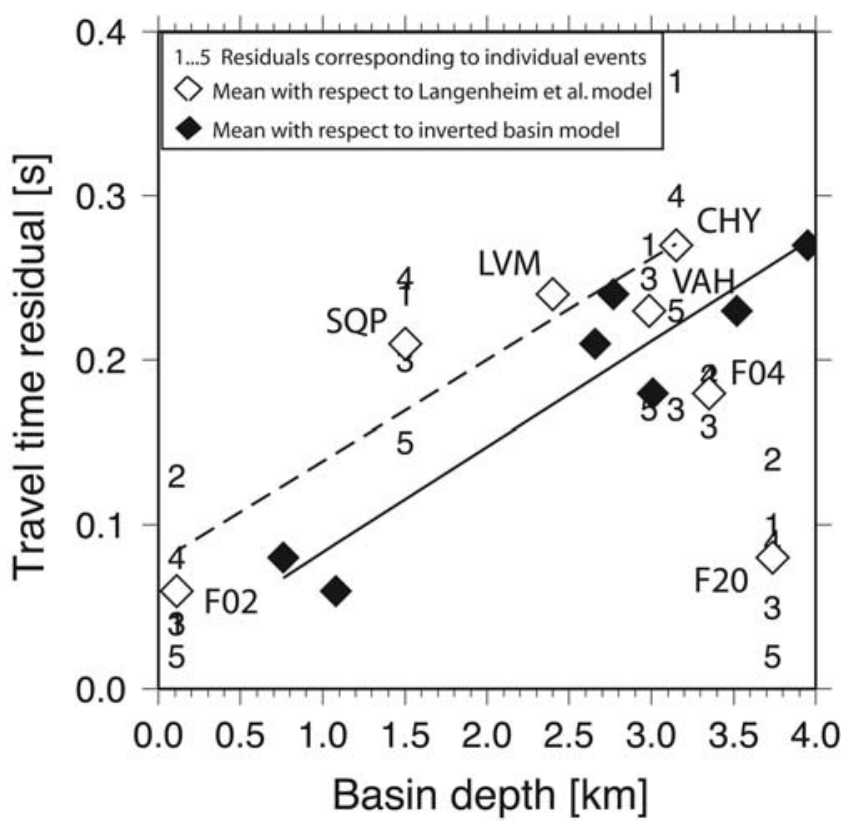

Figure 5. Differential travel-time residuals with respect to the station SGS for five selected teleseismic events with the highest quality of measurements, plotted as a function of basin depth from the Langenheim et al. (2001) model and from a new model from this study. For each station, the travel-time residual versus depth is represented by the number of the corresponding earthquake. Then, the mean of values for differential travel-time residuals with respect to the basin depth from the Langenheim et al. (2001) model is also plotted as an open diamond. The dashed straight line is the best linear fit to the data (excluding F04 and F20). Differential traveltime residuals as a function of the modeled basin depth (the model from Fig. 8) are represented by solid diamonds. The solid straight line is the best linear fit to the data (including F04 and F20) several straight lines that were derived assuming homogeneous basin velocities (Fig. 6, dashed lines). We found that an average compressional velocity of $4.5 \mathrm{~km} / \mathrm{sec}$ approximately matches the observed linear trend for the shallower parts of the basin. Although this velocity is a bit high considering unconsolidated sediments present in the near surface, this value is in agreement with the deep part of the basin from refraction profiling results (Snelson et al., 2004).

Various symbols in Figure 6 show some of representative models from forward modeling of $1 \mathrm{D}$ velocity structure in the basin and surrounding rocks (four resulting models are shown in Table 4). We used a three layer over a half-space model in the basin, and we varied the velocity of the surrounding rocks, assuming vertical incidence of teleseismic waves. Model 1 (circles in Fig. 6; Table 4) is based on the model obtained from preliminary analysis of refraction data by Snelson et al. (2004). Generally, this is a good model, fitting travel-time delays well at CHY, VAH, and LVM. However, it fails to reproduce travel-time delays at station F02 and SQP. The difference between observed and predicted residuals at these two sites is slightly more than $0.05 \mathrm{sec}$; however, this is at or above the error introduced in our differential travel-time measurements. It is known from geotechnical studies (Luke et al., 2002 and Liu et al., 2005), as well as from our finite difference modeling of site response (Rodgers et al., 2006), that the near-surface velocities (300-600 m) in Las Vegas are very low (for shallow shear-wave velocity constraints, see Scott et al., 2004 and Liu et al., 2005). When we introduce a low-velocity layer of $1.5 \mathrm{~km} / \mathrm{sec}$ in a $200-\mathrm{m}-$ thick layer near surface (model 2), we can predict travel-time

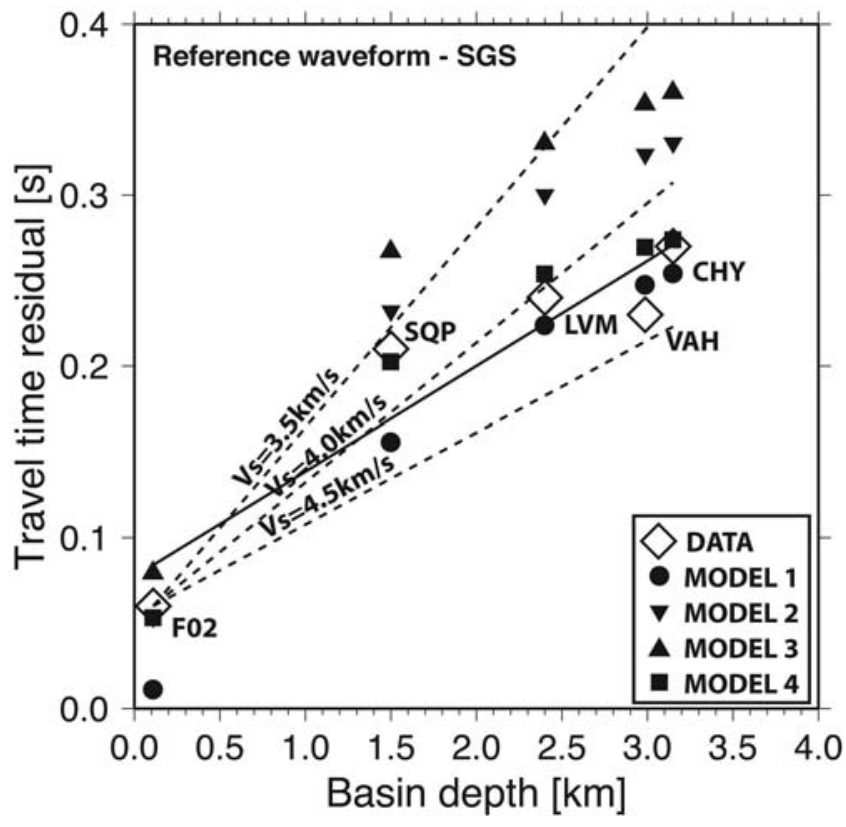

Figure 6. Mean values of travel-time residuals (diamonds) and the best fit (solid line) from Figure 5. Fits derived by forward modeling using structural models with uniform velocity in the basin are shown by dashed lines. Fits derived using 1D models with three layers are shown by various symbols and are described in Table 4. 
Table 4

Structural Velocity Models Used in Forward Modeling of the Observed Differential Travel-Time Residuals (Shown in Fig. 6)

\begin{tabular}{cccccc}
\hline Model & $\begin{array}{c}V_{P}(\mathrm{~km} / \mathrm{sec}) \\
H=0-0.2 \mathrm{~km}\end{array}$ & $\begin{array}{c}V_{P}(\mathrm{~km} / \mathrm{sec}) \\
H=0.2-2 \mathrm{~km}\end{array}$ & $\begin{array}{c}V_{P}(\mathrm{~km} / \mathrm{sec}) \\
H=2 \mathrm{~km} \text { Bottom }\end{array}$ & $\begin{array}{c}V_{P}(\mathrm{~km} / \mathrm{sec}) \\
\text { Hard Rock }\end{array}$ & $\begin{array}{c}\text { rms Data Misfit } \\
(\mathrm{msec})\end{array}$ \\
\hline 1 & 3.5 & 3.5 & 4.5 & 5.5 & 100 \\
2 & 1.5 & 3.5 & 4.5 & 5.5 & 102 \\
3 & 1.125 & 3.8 & 4.8 & 5.93 & 102 \\
4 & 1.5 & 3.8 & 4.8 & 5.5 & 96 \\
\hline
\end{tabular}

The last column shows the rms of travel-time fits for each model with respect to the initial basin topography parameterized with cubic splines. Velocity values from model 4 were used in an initial model for the inversion.

delays at F02 and SQP; however, this model overpredicts delays at other sites (inverted triangles in Fig. 6; Table 4). Model 3 (triangles in Fig. 6; Table 4) used our finite difference site response modeling results, where compressional velocity in the top $200 \mathrm{~m}$ is only $1.125 \mathrm{~km} / \mathrm{sec}$ (this would correspond to shear velocity of $650 \mathrm{~m} / \mathrm{sec}$ using $V_{P} / V_{S}=$ 1.73). This model, with its combination of low near-surfacelayer velocity and faster deep velocity, overpredicts traveltime delays at all stations. Finally, model 4 (squares in Fig. 6; Table 4) is an example of a forward model that fits the observations well. It is a combination of model 2 in that it takes its values for near-surface layer and hard rock velocities and model 3 for the velocities in the deeper portions of the basin. To summarize, we conclude that the existence of a nearsurface low-velocity layer is needed in order to explain the pattern of travel-time delays in the basin. It is difficult, however, to reach definitive conclusions about its thickness and exact velocity values due to a small number of data points and modeling nonuniqueness. We tested different models of soil based on a simple 1D hypothesis, which is quite limiting. The shape of the basin must have a strong influence on the time delays. Therefore, in what follows, we will investigate the geometry of the basin interface further.

\section{Inverse Modeling Using Fast Marching Method}

Our initial results were made dependent on the shape of the basin from Langenheim et al. (2001) and we need not modify the basin geometry. This motivated us to perform inversions based on the fast marching method approach to solve the forward problem of travel-time prediction and a recently developed tomographic inversion scheme (Rawlinson and Urvoy, 2006; Rawlinson et al., 2006). The new scheme contains several innovations, including the use of a robust grid-based eikonal solver, known as the fast marching method (FMM) (Sethian and Popovici, 1999), to solve the forward problem of travel-time prediction. FMM implicitly tracks the first-arrival wavefront by coupling the finite difference solution of the eikonal equation with a narrowband evolution scheme that ensures the causal update of travel time at grid points.
The inverse problem of adjusting model parameters to satisfy data observations is solved using a subspace inversion technique (Kennett et al., 1988). In order to address the nonlinearity of the inverse problem, FMM and subspace inversion are applied iteratively. Within regions bounded by interfaces, velocity is described by a continuum of regular cubic $B$-spline volume elements. Similarly, each interface is independently described by a mosaic of cubic $B$-spline surface elements. In each case, the values of the spline functions are controlled by a regular grid of nodes in spherical coordinates. The complete tomographic scheme allows virtually any class of body wave travel-time data (teleseismic, reflection, refraction, local earthquake) to be inverted for velocity heterogeneity, interface structure, and/or hypocenter location, at a variety of scales. Rawlinson et al. (2006) demonstrate the capability of the new scheme via a series of synthetic tests, while Rawlinson and Urvoy (2006) apply it to a combined active and passive source dataset to image lithospheric velocity and Moho structure beneath Tasmania, southeast Australia.

The LVB dataset comprises 113 travel-time residuals from 21 teleseismic events recorded by nine stations. With this relatively small number of observations, solution nonuniqueness is an important issue, so care needs to be taken when extracting information via this sophisticated tomographic inversion routine. With our limited size dataset, it is important to incorporate as much a priori information as possible and a simple parameterization. Although the teleseismic dataset alone is not capable of reproducing a threedimensional (3D) model of such detail as in Langenheim et al. (2001), adding the independent constraints that the Langenheim model supplies to this a priori information may result in an improved map of basement topography in a sense that it would better fit two independent datasets (seismic and gravimetric). A second source of a priori information comes from the four candidate velocity models shown in Table 4. Seismic phases from distant earthquakes impinge on the crust at very steep angles; therefore, we note that the trade-off between interface geometry and velocity variation cannot be resolved.

In the following series of experiments, the geometry of the interface at the bottom of the basin was allowed to vary, with the overlying and underlying velocity structure held 
constant. The interface is described by a mosaic of cubic $B$ spline surface elements (contours in Fig. 7). The values of the spline functions are controlled by a regular grid of nodes in spherical coordinates. Given that we have restricted our inversion to interface depth variations only, a useful first test is to see which of the four velocity models, used in conjunction with the model of basement topography, best satisfies the observed arrival time residuals. This test only requires the tomography scheme to be run in forward mode. The results, shown in the last column of Table 4, indicate that model 4 (96-msec root-mean-square [rms] data misfit) is the best model, although the differences are not large. This is not surprising, because the relative arrival time residuals will be mainly influenced by the variations in interface structure as opposed to velocity within the basin, which only varies with depth.

The next simulation uses the basement topography model (Fig. 7) and velocity model 4 to define an initial model, and then it applies six iterations of the tomographic inversion routine to try to satisfy the travel-time observations by perturbing the geometry of the interface. As in Figure 7, the interface is parameterized using a $50 \times 50$ grid of control nodes, which means that the inverse problem has 2500 unknowns. Both damping and smoothing regularization are applied to penalize undesirable solutions. A series of tests with different damping and smoothing parameters were carried out in order to find the optimum trade-off between satisfying

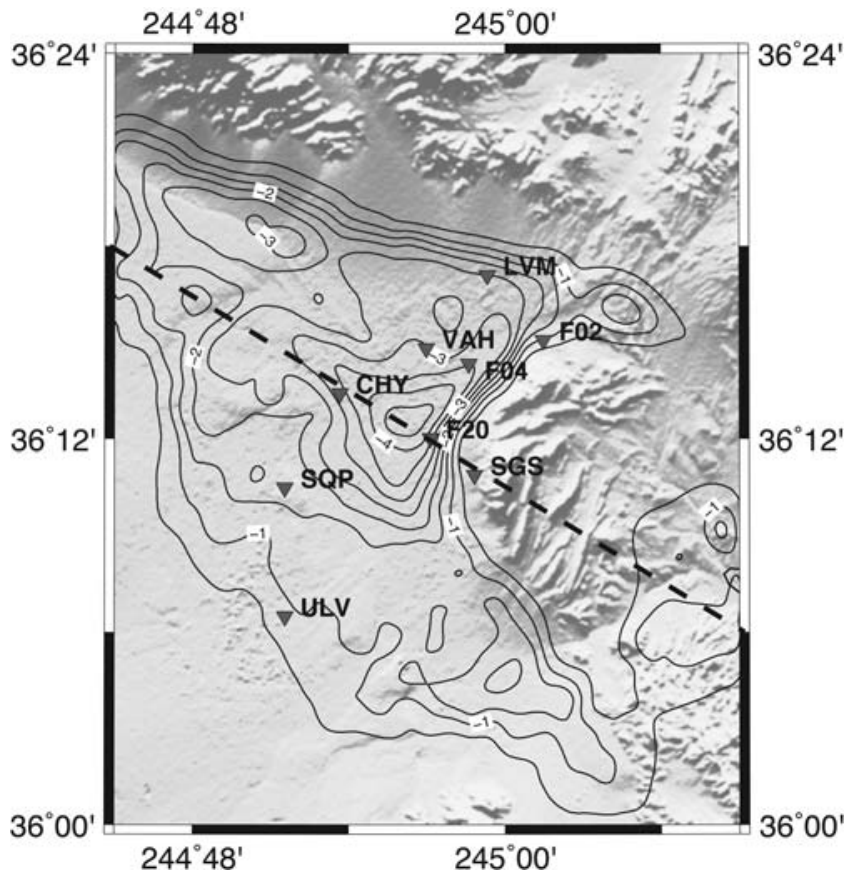

Figure 7. Map of the basin topography used in forward and inverse calculation (as a starting model) using the fast marching method. Thin contour lines are the basin depth estimate from the Langenheim et al. (2001) model represented by a mosaic of cubic $B$-spline surface elements. The dashed line represents the profile shown in Figure 10. the data and obtaining a model that is not too rough or perturbed from the initial model. Figure 8 shows the final model, which has a corresponding rms data misfit of only $59 \mathrm{msec}$, which is near the level of noise in the data. Compared to the initial model, which has an rms data misfit of $96 \mathrm{msec}$, this represents a variance reduction of $61 \%$, which is a significant improvement.

The fact that the initial and final basin models are broadly similar, except for one region (the most changes occurring in the zone between CHY and F20), suggests that the teleseismic arrival time residuals are probably caused by variations in basin geometry and not deeper crustal or upper mantle heterogeneity. However, the level of independent constraint imposed by the teleseismic dataset is not made clear in the results shown in Figure 8, so a final experiment is carried out that does not use the a priori basin model. Instead, the basement in the initial model is a uniform plane at $2 \mathrm{~km}$ depth, with velocity model 4 used to define sediment and basement velocities. Thus, any lateral variation in interface structure of the solution model will be entirely due to the pattern of arrival time residuals. As in the previous example, six iterations of the tomographic scheme are applied, resulting in an rms data misfit of $57 \mathrm{msec}$ for the final model, which is shown in Figure 9. The variations in interface structure only occur in the vicinity of the stations and therefore the corresponding contours at first glance look smoother and less extensive than those in Figures 7 and 8. However, they turn out to be arguably similar to the a priori basement topog-

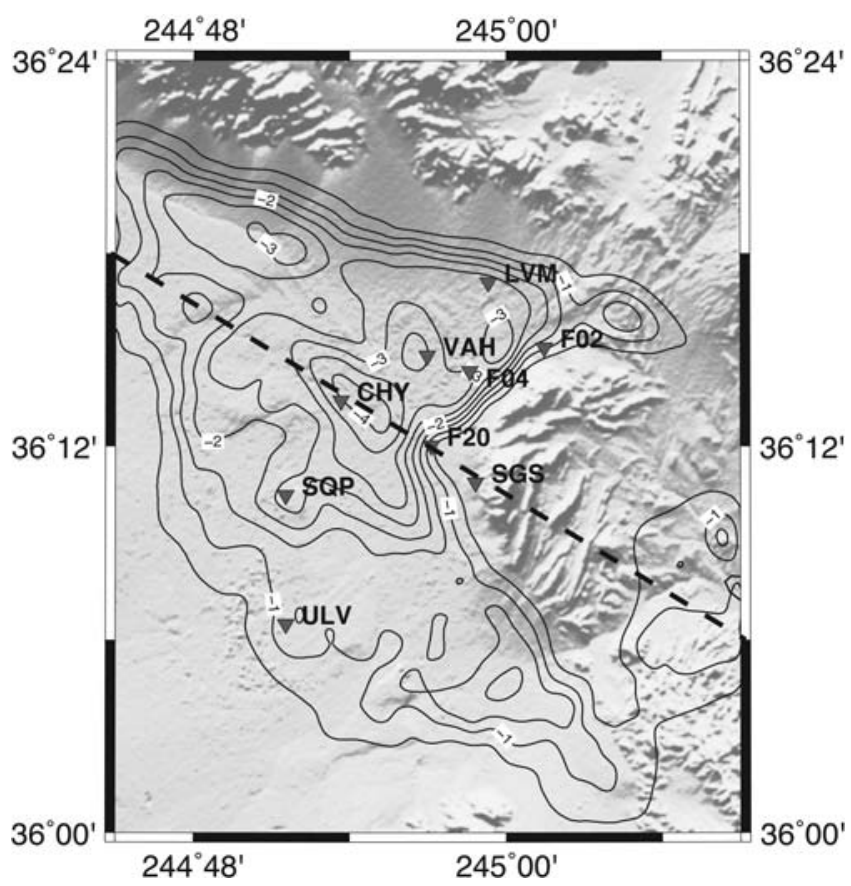

Figure 8. Map of the basin topography obtained in an inverse calculation using basin topography model from Figure 7 as an initial model and 2500 surface nodes as unknowns. The basin depth contours should be compared with those in Figure 7 . The dashed line represents the profile shown in Figure 10. 


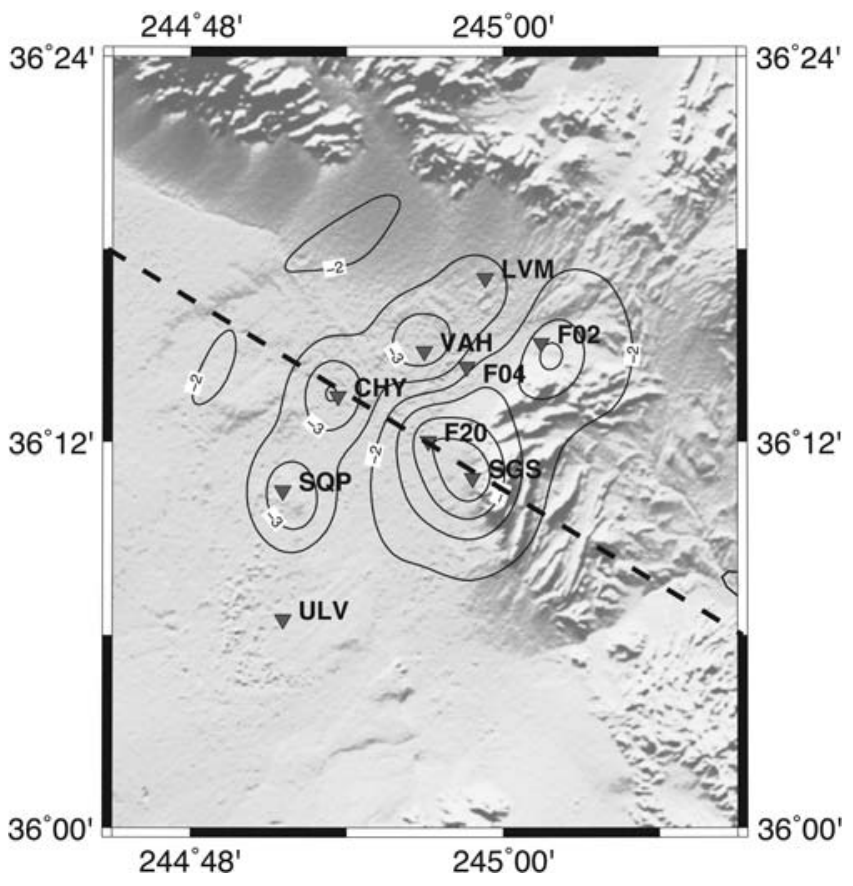

Figure 9. Map of the basin topography obtained in an inverse calculation using a uniform plane at $2 \mathrm{~km}$ depth (no a priori constraints on basin topography). The basin depth contours should be compared with those in Figures 8 and 9. The dashed line represents the profile shown in Figure 10.

raphy model, which confirms our original assumption with regard to the cause of the observed residuals. The level of similarity between the two basement topographies can be better assessed if they are plotted for the same vertical cross section.

The major similarities and differences between the solution models and initial model are highlighted in the greatcircle cross section in Figure 10 (the chosen section through the model is indicated by the thick dashed line in Figures 79). The initial model of the basin shape is indicated by a dashed line, while the final models (described in Figs. 8 and 9) are shown by solid and dotted lines, respectively. In a sense, the model produced in the second test (solid line)

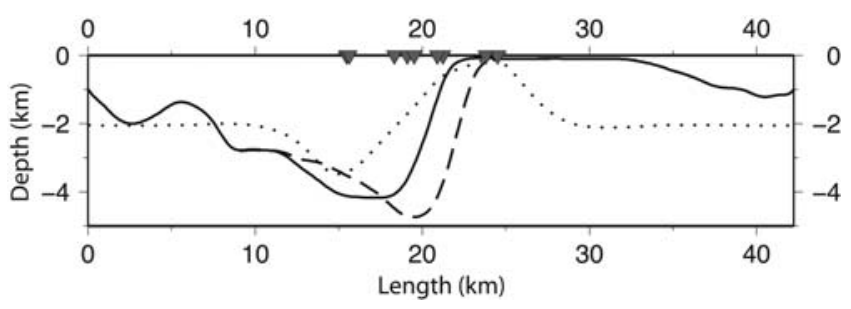

Figure 10. Great-circle cross section through the models shown in Figures 7-9. The initial model (Fig. 7) is indicated by dashed line. The model based on teleseismic data inversion constrained with an initial basin topography (Fig. 8) is shown by a solid line and the model based on teleseismic data inversion only (Fig. 9) is shown by dotted line. can be seen as an amalgamation of the information contained in the initial model (dashed line) and the model based on teleseismic data inversion only (dotted line). While the coverage of teleseismic data is insufficient to independently resolve the steeply dipping wall of the basin, it clearly requires only a thinner layer of sediments beneath station F20, which means that the basin wall in this region is likely to be shifted further west with respect to the Langenheim et al. (2001) model. The size of this shift is less than $2 \mathrm{~km}$, which is less than $10 \%$ of the lateral size of the basin. The model based on teleseismic data inversion only at lengths $25-40 \mathrm{~km}$ looks different than the other two models because there are no data at these lengths and therefore the initially assumed plane at $2 \mathrm{~km}$ depth is not perturbed.

As we have already seen in Figure 5, if the Langenheim et al. (2001) model is used for estimate of the basin depth beneath each station, the travel-time residuals as a function of depth follow a linear trend, except at stations F04 and F20. The dashed line in Figure 5 shows the best-fitting line through five stations with the exclusion of F04 and F20. However, if we now plot the residuals with respect to new estimates of depth beneath each station (from the model shown in Fig. 8), a linear trend is now more obvious, even when F20 and F04 are included, as can be seen from the bestfitting solid line in Figure 5. Thus, it is possible to explain travel-time data with relatively small perturbations of the basin shape from the gravimetry-based model. On the other hand, to explain bipolar observations at F04 might require additional complexity near the contact with Frenchman Mountain on teleseismic ray paths.

\section{Teleseismic Site Response}

The teleseismic site response curves were calculated for all sites with respect to station SGS using standard spectral ratio (Borcherdt, 1970). Fourier amplitude spectra were estimated for two horizontal components using 60-sec-length $S$-wave ground motions and their rms was divided by the same value for site SGS. They are shown by thick lines in Figure 11. We also draw for comparison site response relative to station SGS estimated from regional earthquakes by thin lines (Rodgers et al., 2006). The teleseismic and regional curves are reasonably similar in the range of frequencies for which teleseismic curves were computed. A major feature of site response curves is a peak centered between 0.4 and $0.5 \mathrm{~Hz}$. The observed amplifications are similar at all sites, except at LVM, where they are reduced by the factor of 2 , and F02, which shows a very little amplification in comparison with SGS. These results support our earlier conclusion that the amplification arises from structure in the immediate vicinity of the recording stations, regardless of the direction and nature of the incoming energy-vertically propagating teleseismic $S$ body waves or horizontally propagating regional surface waves. 

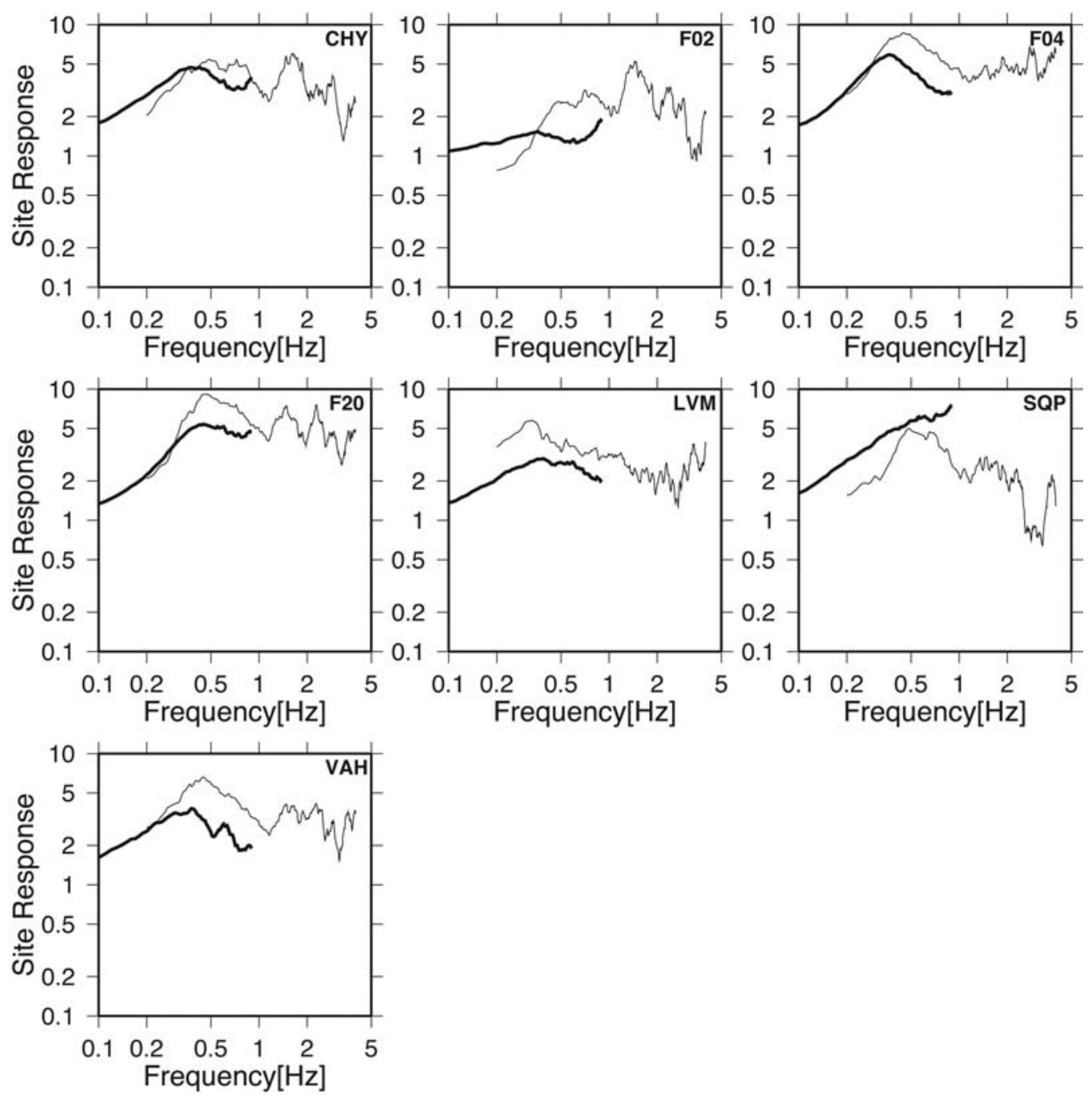

Figure 11. Comparison of teleseismic (thick lines) and regional (thin lines) site response curves with respect to the station SGS. Each line represents the arithmetic average of selected teleseismic and regional responses at a given frequency.

\section{Conclusions}

In this study, we showed using teleseismic $P$-wave travel time that it is possible to detect and extract the effect of the LVB on incoming seismic energy. The observed variations in the travel-time residuals across the basin reach $0.5 \mathrm{sec}$. For example, a comparable result for travel time was obtained in a recent study of the Santa Clara Valley, also a deep sedimentary basin (Dolenc et al., 2005). Our study used waveforms from teleseismic earthquakes at various azimuths to the LVB, yet the observed spatial pattern of differential travel-time delays across the basin remained the same. To explain traveltime observations, we used a forward modeling with some simplified assumptions about ray propagation. We estimated average compressional velocity in the basin to be relatively high $(4.5 \mathrm{~km} / \mathrm{sec})$, which is in agreement with the deepest part of the basin from a recent refraction study (Snelson et al., 2004). We found that introducing a low-velocity near-surface layer, based on previous modeling of site response (Rodgers et al., 2006) and geotechnical shear velocity results (Luke et al., 2002; Liu et al., 2005) explains travel-time data well. We also used a combination of forward and inverse approaches to model the basin topography based on a fast marching method algorithm. Our results indicate that the eastern wall of the basin is likely to be shifted about $2 \mathrm{~km}$ further west with respect to the gravimetry-based model. We found a linear dependence on basin depth of travel-time delays. The fact that the initial and final basin models are broadly similar, except for one region, suggests that the teleseismic arrival time residuals are probably caused by variations in basin geometry and not deeper crustal or upper mantle heterogeneity.

It is worth noting that some of the largest sediment accumulations on the planet exceed $10 \mathrm{~km}$ in depth and extend laterally for tens of degrees. They are accounted for in the global maps of sediment thickness of Laske and Masters 
(1997), which should be used to predict the travel time and waveforms in global studies. Small geological features like the LVB are below the current resolution of existing global sediment maps. The volume of the spatial uncertainty in the location of an earthquake, even after relocation techniques are applied, approaches or exceeds dimensions of a sedimentary basin, such as the LVB. Therefore, besides heterogeneity complexity along the ray paths, correcting for known local geological features near source and receiver is extremely important when analyzing and interpreting data in regional and teleseismic studies of the Earth's structure.

If the eastern margin of the basin can be interpreted as the depth extension of the Frenchman Mountain fault, then the inferred location has consequences for ground motion in Las Vegas. The closer proximity to the urbanized central part of the Las Vegas Valley will likely result in stronger ground motions and greater subsequent damage. Detailed seismic refraction studies may be required to precisely locate this feature.

We reported site response measured from teleseismic data and compared it with previously published site response results for regional earthquakes. Although we do not observe significant variability across the LVB, all of the observed spectral peaks occur near $0.5 \mathrm{~Hz}$. While large teleseismic events cannot be used to estimate site response at higher frequencies than about $1 \mathrm{~Hz}$, these events and corresponding $S$ waves allow estimation of site response for a lower frequency than small regional earthquakes. Frequencies below $1 \mathrm{~Hz}$ are important for large structures, such as buildings taller than 10 stories. Despite the different frequency bandwidth of these measurements, site response in the LVB measured from teleseismic and regional earthquakes is consistent in the band $0.2-1.0 \mathrm{~Hz}$. The similarity of these site response measurements indicates that the amplification is independent of the nature of incident energy, that is, vertically propagating teleseismic $S$ waves or horizontally propagating regional surface waves. This suggests that the amplification arises due to structure directly beneath the recording station.

In conclusion, our observations reinforce previously published basin model and present additional constraints on velocity structure and shape of the basin, which, for instance, can be used to construct initial structural models for 2D and 3D finite difference modeling. With the accumulation of more seismic data of high quality, a more sophisticated modeling will be crucial in the context of recognizing the existing seismic hazard in the LVB. This hazard should be highly appreciated given the circumstances that have the potential to result in a greatly increased structural damage.

\section{Acknowledgments}

We thank F. J. Chávez-García (Associate Editor), L. F. Bonilla, and three anonymous reviewers, whose comments helped to significantly improve the manuscript. We are grateful to many individuals who helped deploy and maintain the stations, and the fire stations, schools, water district, and Nellis for housing the instruments. This work was performed under the auspices of the U.S. Department of Energy by the University of California, Lawrence Livermore National Laboratory, under Contract Number W-7405-Eng-48.

\section{References}

Borcherdt, R. (1970). Effects of local geology on ground motion near San Francisco Bay, Bull. Seismol. Soc. Am. 60, 29-61.

Davis, L., and R. Lynch (1970). Report NVO-1, Seismic response characteristics at Las Vegas, Nevada, from underground nuclear detonations, internal report of the Environmental Research Corporation, 163-203.

Dolenc, D., D. S. Dreger, and S. Larsen (2005). Basin structure influences on the teleseismic wave propagation in the Santa Clara Valley, California, Bull. Seismol. Soc. Am. 95, 1120-1136.

Kennett, B. L. N., E. R. Engdahl, and R. Buland (1995). Constraints on seismic velocities in the Earth from travel time, Geophys. J. Int. 122, 108-124.

Kennett, B. L. N., M. S. Sambridge, and P. R. Williamson (1988). Subspace methods for large scale inverse problems involving multiple parameter classes, Geophys. J. 94, 237-247.

Langenheim, V., J. Grow, R. Jachens, G. Dixon, and J. Miller (2001). Geophysical constraints on the location and geometry of the Las Vegas Valley shear zone, Nevada, Tectonics 20, 189-209.

Laske, G., and G. Masters (1997). A global digital map of sediment thickness, Eos Trans. AGU 78, F483.

Liu, Y., and B. A. Luke (2004). Role of shallow soils in defining seismic response of a deep basin site subjected to high-energy explosive loading, Proceedings of the 11th International Conference on Soil Dynamics \& Earthquake Engineering, D. Doolin, A. Kammerer, T. Nogami, R. B. Seed and I. Towhata (Editors), University of California, Berkeley, 2, 17-24.

Liu, Y., B. A. Luke, S. Pullammanappallil, J. N. Louie, and J. Bay (2005). Combining active- and passive-source measurements to profile shear wave velocities for seismic microzonation, in Geo-Frontiers, Austin, Texas, 24-26 January 2005.

Louie, J. N., J. G. Anderson, B. A. Luke, C. M. Snelson, W. Taylor, A. Rodgers, D. McCallen, H. Tkalčić, and J. Wagoner (2004). Seismic wave amplification in Las Vegas: site characterization measurements and response models (Abstract S43A-0979), Eos Trans. AGU, 85, no. 47 (Fall Meet. Suppl.), S43A-0979.

Luke, B. A., J. N. Louie, H. E. Beeston, V. Skidmore, and A. Concha (2002). Las Vegas seismic response project: measured shallow soils velocities (Abstract S12B-1189), Eos Trans. AGU, 83, no. 47 (Fall Meet. Suppl.), S12B-1189.

McEwan, D. J. (2005). A seismological study of the Las Vegas basin, NV: investigating basin depth and shear velocity structure, Master's Thesis, University of Nevada, Las Vegas, $117 \mathrm{pp}$.

Patton, H., and S. Taylor (1984). $Q$ structure of the Basin and Range from surface waves, J. Geophys. Res. 89, 6929-6940.

Plume, R. W. (1989). Ground-water conditions in Las Vegas Valley, Clark County, Nevada, U.S. Geol. Surv. Water Supply Pap. 2320-A, A1-A15.

Rawlinson, N., and M. Urvoy (2006). Simultaneous inversion of active and passive source datasets for 3-D seismic structure with application to Tasmania, Geophys. Res. Lett. 33, L24313, doi 10.1029/ 2006GL028105.

Rawlinson, N., M. de Kool, and M. Sambridge (2006). Seismic wavefront tracking in 3-D heterogeneous media: applications with multiple data classes, Explor. Geophys. 37, 322-330.

Rodgers, A., H. Tkalčić, D. McCallen, S. Larsen, and C. M. Snelson (2006). Site response in Las Vegas Valley, Nevada from NTS explosions and earthquake data, Pageophysics 163, 55-80.

Scott, J. B., M. Clark, T. Rennie, A. Pancha, H. Park, and J. N. Louie (2004). A shallow shear-wave velocity transect across the Reno, Nevada area basin, Bull. Seismol. Soc. Am. 94, no. 6, 2222-2228.

Sethian, J. A., and A. M. Popovici (1999). 3-D traveltime computation using the fast marching method, Geophysics $\mathbf{6 4 , 5 1 6 - 5 2 3 .}$ 
Slemmons, D. B., J. W. Bell, C. M. dePolo, A. R. Ramelli, G. S. Rasmussen, V. E. Langenheim, R. C. Jachens, K. Smith, and J. O’Donnell (2001) Earthquake hazard in Las Vegas, Nevada, in Proceedings of the 36th Annual Symposium on Engineering Geology and Geotechnical Engineering, B. Luke, E. Jacobson and J. Werle (Editors), Las Vegas, Nevada, 447-460.

Snelson, C. M., D. J. McEwan, A. C. Hirsch, and S. A. Zaragoza (2004) Imaging the Las Vegas basin: results from recent seismic refractions experiments (Abstract S34A-07), Eos Trans. AGU 85, no. 47 (Fall Meet. Suppl.), S34A-07.

Stidham, C. (1999). Three-dimensional crustal structure influences on wave propagation and generation of strong ground motion in the greater San Francisco Bay region, Ph.D. Thesis, University of California, Berkeley.

Su, F., J. G. Anderson, S. Ni, and Y. Zeng (1998). Effect of site amplification and basin response on strong motion in Las Vegas, Nevada, Earthq. Spectra 14, 357-376.

Tabor, L. (1982). Geology of the Las Vegas area, U.S. Department of Energy, Nevada Operations Office, Las Vegas, Nevada.

Tkalčić, H., A. Rodgers, C. M. Snelson, and D. McEwan (2003). Comprehensive analysis of broadband seismic data in Las Vegas Valley (Abstract S11D-0323), Eos Trans. AGU 84, no. 46 (Fall Meet. Suppl.), S11D-0323.

Wernicke, B., G. Axen, and J. K. Snow (1988). Basin and Range extensional tectonics at the latitude of Las Vegas, Nevada, Geol. Soc. Am. Bull. 100, 1738-1757.
Wessel, P., and W. H. Smith (1991). Free software helps map and display data, Eos Trans. $A G U$ 72, 441 .

Research School of Earth Sciences

The Australian National University

Canberra ACT 0200, Australia

Hrvoje.Tkalcic@anu.edu.au

(H.T., N.R.)

Earth Science Division

Earth and Energy Sciences Department

Lawrence Livermore National Laboratory

Livermore, California 94550

(A.J.R.)

Department of Geoscience

University of Nevada, Las Vegas

4505 Maryland Parkway

MS 4010

Las Vegas, Nevada 89154-4010

(D.J.M., C.M.S.)

Manuscript received 1 December 2005 